\begin{tabular}{|ll|}
\hline $\begin{array}{l}\text { Social Work/Maatskaplike Werk Vol } 57 \text { No 1; Issue 2 } \\
\text { http://socialwork.journals.ac.za/pub }\end{array}$ & doi:http://dx.doi.org/10.15270/52-2-904 \\
\hline
\end{tabular}

EMPLOYEE ASSISTANCE PROGRAMMES AND OCCUPATIONAL SOCIAL WORK: INTERRELATED WITH DISTINCT FEATURES

Lourie Terblanche, Thula Gunya, Magalane Maruma, Kelebogile Mbuyisa, Tsholofelo Maseko, Kedibone Mojapelo, Nozazi Myeni, Marisa Pretorius, Warren Tyson

A research project was undertaken to explore the differences and similarities between employee assistance programmes (EAPs) and occupational social work (OSW). This was done in order to provide clear and distinct guidelines to potential employers/corporate clients regarding a choice between occupational social work (OSW) and employee assistance programmes (EAP) when they are considering the introduction of programmes and services to promote the psycho-social functioning and productivity of employees and the successful operation of the workplace at large.

In addition to the literature study on these two concepts, occupational social work and employee assistance programmes, an empirical study was conducted, consisting of a qualitative and a quantitative component. The qualitative study was performed by a number of researchers who used the same data-collection instrument, developed by the group of researchers under the supervision of the main author of this article. Data were, however, collected in different ways, i.e. one-on-one personal interviews, interviews via e-mail, and focus group interviews. The quantitative part was performed through an on-line survey with a self-developed questionnaire, also under the supervision of the main author.

Findings confirmed that both the EAPs and OSW deal with work-related, personal, interpersonal and productivity issues. The findings further confirmed that the kind of employee issues addressed dealt with a range of concerns, including substance abuse, stress, trauma, financial difficulties, conflict, absenteeism, employee development and bereavement.

Despite a number of similarities between OSW and EAPs, very few differences have been confirmed other than the variables impacting on structure and legalisation, which also confirms why the EAP and the OSW cannot be used as interchangeable concepts.

Keywords: core technologies, employees, Employee Assistance Programmes (EAPs), EAP standards, Occupational Social Work, scope of service 



\title{
EMPLOYEE ASSISTANCE PROGRAMMES AND OCCUPATIONAL SOCIAL WORK: INTERRELATED WITH DISTINCT FEATURES
}

\author{
Lourie Terblanche, Thula Gunya, Magalane Maruma, Kelebogile Mbuyisa, Tsholofelo \\ Maseko, Kedibone Mojapelo, Nozazi Myeni, Marisa Pretorius, Warren Tyson
}

Professor Lourie Terblanche, Department of Social Work and Criminology, University of Pretoria, Pretoria, South Africa assisted by the following Master's students at the same Department: Ms Thula Gunya, Mr Magalane Reuben Maruma, Mrs Kelebogile Mbuyisa, Mrs Tsholofelo Maseko, Ms Kedibone Mojapelo, Ms Nozazi Myeni, Mrs Marisa Pretorius, Mr Warren David Tyson.

Keywords: core technologies, employees, Employee Assistance Programmes (EAPs), EAP standards, Occupational Social Work, scope of service

\section{INTRODUCTION}

Whether employees' issues are work-related affecting their home life or home-related affecting their work life, the employee is experiencing imbalances relating to some form of stress, which ultimately affects their productivity and job performance, as well as the workplace organisation.

Because both performance and productivity are affected, the consequence is a disruption of the employee's work-life balance. In some instances the employee, through utilisation of personal resources and support systems, is able to rectify the imbalance in their work life equilibrium and thereby restore order. However, in other cases this is not possible. Due to the holistic and systemic nature of human beings, and the natural overflow of (negative) energy from one part of the employee's life to another, the employee finds it difficult to resolve his work- or home-related issues without assistance and thus often requires some sort of external intervention. Because of the impact that employees' stress has on their job performance and productivity, there is a need for workplace programmes that provide personal and social services to employees, also referred to as employee assistance programmes or EAPs (Mogorosi, 2009:343).

In the late nineteenth and early twentieth centuries, occupational social work (OSW) was recognised as one of the core areas of social work intervention, evolving from the principles and background of generic social work practice into a specialised field, subsequently forming part of EAPs. Occupational social workers, as part of EAPs, were either employed by the organisation or hired as part of outsourced services to render counselling services and interventions to employees and their families.

Van Breda (2009:285) provides a similar account by indicating that, based on the working definitions of OSW and EAP in Akabas (1995) and Barker (2003) respectively, both disciplines identify employees as the sole client system, leading to EAP and OSW becoming indistinguishable. However, Van Breda (2009:285) adds that "this view is not universally accepted; indeed, it has been increasingly challenged in recent years". Since the inception of EAP and OSW in the workplace, both internationally and locally, there has been a strong link between the two disciplines. The more recent opinion could indeed be viewed as a definite change, since during the latter half of the $20^{\text {th }}$ century there has been strong advocacy for the development of OSW beyond the field of EAP, into a distinctive practice domain (Iversen, 1998:556). Over time, however, EAP has dominated the OSW scene, and EAP and OSW were consequently often used and referred to interchangeably (Mor Barak \& Bargal, 2000:3).

Subsequently, within the South African context, EAP (since the mid-1980s) and OSW (since the mid1930s) have been recognised as independent fields of practice rendering services to both employers and employees alike (Du Plessis, 1994). Du Plessis further indicates that both disciplines have grown considerably since their introduction into the South African occupational setting. Due to the increasing interest in both fields, and possibly because of their need to attain recognition and professional status 
within their respective disciplines and fields of practice, employee assistance professionals and occupational social workers established professional bodies that would ultimately serve the interests of their members and the members' client systems alike.

In 1997 the Employee Assistance Professionals Association of South Africa (EAPA-SA) became an official branch of the Employee Assistance Professional Association based in the USA, while the South African Occupational Social Work Association (SAOSWA), formerly known as the Forum for Occupational Social Workers, was established in 2003 (EAPA-SA, 2016; SAOSWA, 2017), although without any international affiliation.

However, the researchers are of the opinion that, despite the struggle to establish the autonomy of EAP and OSW practice, there still seems to be confusion about the difference between them within the occupational setting with regard to their purpose, role, function, goals and objectives, scope of practice, service delivery approach and client systems. This challenge was further complicated by the movement towards the integration of concepts such as wellness, work-life balance and EAPs (Mulvihill, 2005:64).

In 1984 the National Association of Social Workers of the USA suggested that work-related problems influence employees and often overflow into problems that occur at home or in the community. The converse also applies, where problems at home and within the community affect the individual's work (Maiden, 2001:125). Thus, the assumption is made that humans, as holistic beings, are unable to compartmentalise their lives by completely separating one part from another. Human beings consist of a variety of elements that are expected to work in harmony, with a natural intermingling and overflow between these elements, especially when it comes to dealing with stress, conflict and crises. This argument supports the decision to apply the ecological systems perspective as the theoretical framework for this study.

Thus, the researchers were convinced about the need to conduct the proposed research study in order to theoretically and practically conceptualise EAP and OSW, in an attempt to determine their similarities and differences.

\section{THEORETICAL FRAMEWORK}

The researchers adopted the ecological systems theory of development (EST) as developed by Urie Bronfenbrenner, as it explores and describes EAP and OSW each as focusing on an individual employee/system consisting of interdependent and interrelated parts. The study aims to determine the similarities and differences between EAP and OSW as change agents when focusing on the employees confronted by the sub-systems of their respective workplace macro systems by defining their purpose, role, function, scope of practice and client systems within the workplace macro system (Khubeka, 2015:10; Payne, 2015:193-194). Although the intervention within each of the disciplines under discussion is more prominently focused on the workplace as the macrosystem of which the employee forms a part, acknowledging the role of the microsystem, mesosystem and chronosystem becomes a natural part of the therapeutic intervention or counselling process. As such, a decision in favour of the ecological systems theory, which was originally developed to describe how a child's development is affected by his/her social relationships, seems to be appropriate. In this study EST is applied to adult employees.

The importance of the workplace was highlighted by Parast and Niya (2015: 1120), who state that "growing numbers of people lack the comfort of a nuclear family, a religious or fraternal community, or even a tight-knit neighbourhood, thus the job site has become a place to build stable, caring, long-term relationships". This view correlates with the mesosystem aspect of Bronfenbrenner's ecological systems theory. 


\section{OCCUPATIONAL SOCIAL WORK AND EMPLOYEE ASSISTANCE PROGRAMMES - TWO DISCIPLINES RUNNING CONCURRENTLY}

The worksite, where both OSW and EAP are practiced, is an important setting that impacts on the social, mental and physical wellbeing of the employee. A healthy workplace environment can induce many positive changes such as a healthier workforce, increased morale, reduced absenteeism and, in turn, increased productivity. Conversely, an unhealthy and hazardous workplace can increase mortality and morbidity, lower the worker's quality of life, and escalate health-care costs (Chu, 1994:182).

Clarification of concepts is crucial when the rationale of the study is precisely to clarify possible confusion between two key concepts, i.e. occupational social work and employee assistance programmes.

Employee refers to "a person whose employment is governed by a contract of service or other relevant employment laws" (Standards Committee of EAPA-SA, 2015:2).

The concept of employee assistance programmes refers to "services offered by employers to their employees to help them overcome problems that may negatively affect job satisfaction or productivity" (Barker, 2003:141) and "the work organisation's resource based on core technologies or functions to enhance employee and workplace effectiveness through prevention, identification and resolution of personal and productivity issues" (Standards Committee of EAPA-SA, 2015:2).

Terblanche (2019:7) provides a definition of the EAP, which is taken as guide for purposes of this article:

An Employee Assistance Programme (EAP) is a strategic work-based intervention programme designed to enhance the psycho-social well-being of all individual employees and the wellbeing of the employer as corporate client towards improved productivity of the workforce at large. The goal is to provide proactive and reactive interventions, through the application of acknowledged core technologies, for the early identification and/or resolution of both work and personal challenges that may adversely affect performance and well-being. These challenges and issues may include, but are not limited to relationships, health, trauma, substance abuse, gambling and other addictions, financial problems, mental and psychiatric disorders, communication, legal, structural and transformational issues.

The concept employer refers to "a person or an institution who hires employees and offers remuneration in exchange for labour" (Standards Committee of EAPA-SA, 2015:2).

The following key concepts relevant to the study are also defined.

- EAP Coordinator: The Employee Assistance Coordinator will provide general employee assistance administrative support to clients and colleagues to enable operational administrative integrity of employee assistance practices. The nature of the services are non-clinical.

(https://pbdesig.saqa.org.za/viewProfessionalDesignation.php?id=839).

- EAP Practitioner: "A person (not necessarily professionally trained) performing EAP-specific or related tasks, i.e. referral, liaison, training, marketing, evaluating" (Standards Committee of EAPASA, 2015:2). (https://pbdesig.saqa.org.za/viewProfessionalDesignation.php?id=495).

- EAP Professional: "A professionally trained person providing an EAP service, including clinical EAP-specific or related tasks, i.e. therapy, counselling" (Standards Committee of EAPA-SA, 2015:2). (https://pbdesig.saqa.org.za/viewProfessionalDesignation.php?id=496).

- EAP Specialist: A strategic advisor to executives and policy-makers; effecting programme design, profiling, strategic planning, policy and procedures and the application of monitoring and evaluation practices in EAP. (https://pbdesig.saqa.org.za/viewProfessionalDesignation.php?id=840).

A number of common variables appear according to the views of different authors on occupational social work, i.e. policies providing for social work services rendered in the workplace to employees, trade unions and employers as part of the broader work community through a variety of interventions (Akabas, 1995: 177, Mogorosi, 2009:345; Straussner, 1989:21). 
Another definition of occupational social work is "a specialised field of social work practice which addresses the human and social needs of the work community within a developmental approach through a variety of interventions which aim to foster optimal adaptation between individuals and their environment" (White Paper on Social Welfare, 1997:3), which reflects another component being added, namely the developmental social work approach - which brings this definition in line with the overall approach as was accepted for social work as a profession in the South African context (Patel, 2016:126127).

For purposes of this article, the following definition for occupational social work has been formulated:

Occupational social work is a specialised field of social work, targeted at enhanced productivity in the entire workplace by enhancing psycho-social functioning through professional services based on policies, procedures and programmes to the benefit of individual employees including operational workers, union members, supervisors and management.

Service Provider - normally in the context of the EAP - refers to "an [external] agency providing professional services to clients and corporate clients in accordance with a formal contract" (Standards Committee of EAPA-SA, 2015:2). The term is seldom, if ever, used in the context of OSW. One reason for the absence of service providers in the OSW context may just be the fact that most OSW practitioners are employed in the context of in-house programmes being delivered. The SAPS employs social workers to concentrate on and empower police officers to deal with and/or improve their social wellbeing and coping ability as unique individuals (Stutterheim \& Weyers, 2004:2).

The purpose of this section is to contextualise EAP and OSW theoretically, in context of services being rendered to address unhealthy and/or hazardous workplaces and in so-doing enhance the productivity and psycho-social functioning of the relevant employees. In order to compare EAP and OSW, each field of practice will be described individually and broken down into separate components. These will be discussed in the following sections.

\section{Employee Assistance Programmes}

In the following sections the researchers describe various aspects and components of the EAP. The purpose of this section is to give an outline of EAP service delivery and practice models, core technologies and functions, scope of practice, client systems and statutory requirements for practice and registration with professional bodies.

As the South African political, economic and social climate fluctuates and changes, organisations and employees alike will continue to experience the effect of unrealistic and excessive demands placed on resources. Thus the researchers are of the opinion that the demand for EAP and workplace-based interventions will steadily increase as employees are expected to perform under challenging circumstances, making it particularly difficult for them and their families to cope physically, psychologically, socially and spiritually, hence influencing their productivity and job performance.

The confusion created by the debate around whether EAPs and wellness programmes should become integrated or not should also not be ignored. EAPs had to face pressure from certain practitioners from these two fields whether to continue offering services separately or as an integrated programme (Gornick \& Blair, 2005:19 - 24). As such, deciding on a suitable practice model becomes an enormous responsibility. Despite such a decision often being guided by the preferences of the corporate client, innovative design and the resulting implementation of programmes are becoming of crucial importance in a highly competitive environment.

\section{Service delivery and practice models}

The Employee Assistance Professionals Association of South Africa (2015) has stipulated specific standards for EAP practice and service delivery, as published in their "Standards for Employee Assistance Programmes in South Africa". The purpose of this document is to guide employee assistance practitioners and professionals in terms of EAP service delivery. The stated purpose of the Standards is 
to "provide a benchmark for EAP practice and service delivery; promote the establishment of quality programmes; describe EAP scope of service; operationalise programme standards and guidelines; educate the workplace community about EAP services; serve as a guide for EAPA-SA membership and related professionals; and to enhance the quality and functioning of existing Employee Assistance Programmes" (Standards Committee of EAPA-SA, 2015:1).

As stated in EAPA-SA's definition of EAP, practice is based on core technologies or functions, which will be discussed in the next section.

\section{Scope of service, core technologies and functions}

The Standards Committee of EAPA-SA (2015:1) regards the following aspects as core technologies and/or functions of EAPs, although slightly different from the original work, which was published by Roman and Blum (1985) (Attridge, 2009:386). Roman and Blum (1985) concluded initially with a total of six core competencies, but with a seventh one added as a result of research amongst a large number of EAPs, at the time conducted throughout the USA. The core technologies were formulated as the conclusion on which common functions were performed by those different EAPs. EAPA-SA supports a view, different from the above-mentioned viewpoint, arguing in favour of avoidance of duplication of the same activity, i.e. not recognising some of the steps in the therapeutic process, which Roman and Blum acknowledge as separate technologies in themselves.

- Training and development: Training and development of stakeholders, including managers, supervisors and unions, concerning effective management of employees who are experiencing challenges; enhancing the work environment; and improving employee productivity and job performance.

- Marketing: The promotion and 'selling' of EAPs, services and interventions to stakeholders, providing the necessary information on programme details and content, accessibility and confidentiality, as well as encouraging participation and utilisation.

- Therapeutic intervention: Therapeutic intervention for employees and their families experiencing personal and work-related problems that might affect job performance. These services consist of risk identification, assessment, motivation, short-term intervention, referral, monitoring, follow-up, reintegration and aftercare services. Roman and Blum (1985) acknowledged, for instance, 'constructive confrontation' as an additional core technology.

- Consultation by work organisations: Consultation with work organisations to proactively identify and address inherent trends stemming from personal or organisational issues.

- Networking: Establishing and maintaining effective relations with internal and external role-players and service providers.

- Monitoring and evaluation: monitoring and evaluation of EAP services and interventions relating to the work organisation and individual job performance.

The above core technologies define the functions of EAP practice and service delivery. The following section describes the scope of practice of the EAP, consisting of various components which form the foundation upon which the various EAPA-SA Standards are established (Standards Committee of EAPASA, 2015:4-34). The reader may develop the impression that there is some overlap between these categories of standards and the core technologies discussed above. The explanation, however, is that these categories of service should be interpreted as a reflection of the functionality of the EAP itself in performing the core technologies. The absence of any of the core technologies or these categories of EAP standards should be seen as placing the EAP at risk of malfunctioning. To be more specific, should the EAP not be well designed and implemented, such EAP may not be sufficiently equipped to perform one or more of the core technologies and as such the EAP cannot be seen as effective. 
- Programme design: deals with the establishment of an EAP advisory committee, compiling of an organisational profile, identification and selection of appropriate service delivery models and procedures and selection of appropriate costing models.

- Implementation: includes EAP policy development, formulation of operational guidelines for policy implementation, and formulation of an implementation plan.

- Management and administration: includes staffing of the EAP, providing for professional consultation, supervision, professional development of EAP staff and professional liability insurance. Crucial related issues are also included: promoting confidentiality, disclosure of information, record keeping and overarching ethics.

- Clinical services: include trauma management, crisis intervention, assessment, referral, short-term intervention, case monitoring and evaluation, aftercare and reintegration.

- Non-clinical services: these entail organisational consultation, EAP training, and marketing.

- Preventative services: these refer to the development of holistic and proactive prevention services.

- Networking: encompasses the building of networks with internal and external stakeholders and service providers - also referred to as stakeholder management.

- Monitoring and evaluation: The effectiveness of EAP services and interventions are continuously monitored and evaluated (Naicker \& Fouché, 2003:26-28).

The above section has described the scope of EAP practice by identifying the specific actions required in the design, implementation, management and administration of employee assistance programmes, and the rendering of services promoted through networking, monitoring and evaluation.

The following section will address the EAP client systems.

\section{Client systems}

The Standards Committee of EAPA-SA (2015:3) identifies the following client systems as target groups for comprehensive service delivery: the organisational management and supervisory structures; worker organisations; and employees and their families. EAP services are rendered to these client systems by EAP coordinators, practitioners, professionals and specialists as part of a comprehensive package.

\section{Requirements for practice: registration with statutory bodies and professional associations}

The Employee Assistance Professionals Association of South Africa (2016) indicates the following requirements for registration as an individual member:

- Proof of employment in the field of employee assistance programmes and/or wellness;

- Proof of the successful completion of a short course in EAP (as part of accreditation);

- Proof of registration with a statutory body;

- Proof of chapter involvement / attendance of at least two meetings per annum.

During 2015 the South African Qualifications Authority (SAQA) (2015) recognised EAPA-SA for the first time as a "professional body constituted to represent and/or regulate a recognised community of expert practitioners". However, there is no specific legislative or statutory body currently available which governs EAP practice in South Africa. As stipulated above, one of the requirements for membership with EAPA-SA is "proof of registration with a statutory body". This means that any practising professional, such as a social worker or psychologist, who seeks to join EAPA-SA, must be registered with the respective statutory body, be it the South African Council for Social Services Professions or the Health Professions Council of South Africa, as required by legislation. 
SAQA, however, distinguishes and recognizes four designations, as was pointed out earlier, namely EAP coordinator, EAP practitioner, EAP professional and EAP specialist (Terblanche, 2018:450). As mentioned, each designation provides for specific tasks and roles to be performed.

\section{Occupational Social Work}

"Occupational social work is an emerging profession with the potential to positively influence the workplace. However, in order to make a positive contribution to solving current workplace dilemmas, occupational social workers need to keep abreast of workplace developments" (Dorkin, 2009:1). Occupational social workers endeavour to develop the fit between the various client systems occurring within the occupational setting, striving towards gainful employment for employees (Mor Barak \& Bargal, 2000). The primary purpose of OSW is to enhance the social wellbeing and functioning of the work organisation as a community through contributing towards achieving the objectives of the work organisation and to its effectiveness (Kruger \& Van Breda, 2001:947).

The purpose of this section is to give an outline of OSW, service delivery and practice models, core technologies and functions, scope of practice, client systems, and statutory requirements for practice and registration with professional bodies.

The following section will address OSW practice models and service delivery.

\section{Practice models and service delivery of $\mathrm{OSW}$}

The White Paper on Social Welfare (1997) prescribes a developmental approach to social service delivery. As OSW is based on generic social work principles, as stated earlier, and falls within the social service spectrum, service delivery should be focused on development with the intention of building human capacity; it should be needs-based and people-centred. Thus, OSW services should promote and contribute to the development of skills, play a facilitative role in a changing environment, and remain dynamic and able to undergo change in order to remain relevant (Kruger \& Van Breda, 2001:947). Because there are occupational social workers working within EAP, the White Paper is relevant and applicable to EAP concerning the adoption of a developmental approach to service provision within the occupational setting.

Kruger and Van Breda (2001:948-951) suggest the occupational social work practice model as a point of departure for OSW practice. This model identifies three client systems, namely the employee as a person, the person as an employee, and the organisation as a client. The authors use the term 'binocular vision' to describe the ability to have both a 'microscopic' view of everyday issues of the individual and their family, and a 'telescopic' view of organisation-related issues and problems, giving the occupational social worker the ability to look at the situation in perspective. The occupational social work practice model refers to four intervention positions, relating to different focal areas of OSW practice and services.

The four positions of the social work practice model are:

1) restorative interventions, rendering problem-solving services to the client as an individual, couple, family, group, or community;

2) promotive interventions, rendering services that enhance and promote social functioning of clients;

3) work-person interventions, rendering services that focus on what occurs between the person as an employee and the various workplace systems; and

4) workplace interventions, rendering services that focus specifically on the workplace itself, the organisation, management and other workplace structures (Kruger \& Van Breda, 2001:948-951).

The social work practice model describes a comprehensive and effective approach to OSW practice and service delivery, by implication based on certain core technologies and functions of OSW. 


\section{Core technologies and functions of OSW}

Akabas (1995:177) and Mogorosi (2009:344) identify the following as core functions of OSW services and work-based programmes.

- Consultation: occurs within the workplace organisation with management and stakeholders concerning identification and management of needs and trends regarding personal and organisational issues.

- Training and development: entails teaching and facilitation of job-specific social skills and employee development.

- Support services: provide support services to employees and their families regarding personal and work related issues that contribute towards social functioning.

- Client assessment and intervention: involves social work methods and skills, including short-term and crisis interventions.

- Marketing: entails proactive promotion of OSW services and programme utilisation thus contributing to the work organisation's goals and objectives.

- Networking: includes advocating on behalf of clients, and development of relationships with and referral to community-based service providers.

These core technologies have, however, not been reflected in any guidelines or manuals for OSW in the South African context, based on empirically gathered data.

The following section will address the scope of practice of OSW.

\section{Scope of practice of $\mathrm{OSW}$}

Van Breda (2009: 286- 296), supported by the Social Service Professions Act 110 of 1978, section 28(1)(gA): Regulations relating to the registration of a specialty in occupational social work (2010), identifies OSW services as:

- Work-focused assessment of needs or problems of various workplace client systems;

- Work-focused interventions with individuals, groups, employing organisations and communities;

- Work-family interventions to promote family wellness in relation to the impact of employment;

- The promotion of human rights practice, social justice and productivity; and

- Work-focused policy and programme development.

Williams (2016:130) confirmed the above view when referring to the responsibility of occupational social workers as specialists who are "able to balance and assimilate organisational, work-person, promotive and restorative interventions that contribute to the optimal functioning of the organisation, the police officers, their immediate family members, support personnel and the community at large".

The practices can, however, only be implemented by focusing on the following client systems.

\section{Client systems within $\mathrm{OSW}$}

Kruger and Van Breda (2001:948) identify three client systems in OSW: the employee as a person, the person as an employee and the organisation as a client. The authors suggest that the first instance, the employee as a person, describes the employee in their private capacity referring to the employee's personal problems, including his/her family system. Second is the person as an employee, where the attention of the social worker turns to the employee's work-related needs and problems. The social worker enables the employee to perform his/her duties as prescribed by the organisation. Finally, there is the organisation as client, where the organisation refers to the workplace. 
The Social Service Professions Act 110 of 1978, section 28(1)(gA): Regulations relating to the registration of a specialist in OSW (2010), classifies client systems as recipients of occupational social work services, in line with Kruger and Van Breda, but expands on this as follows: these recipients include employees, and their family systems, forming part of a work system; the employing organisation; and communities that have operational or geographical links to the employing organisation.

The above perspective takes into consideration the systemic nature and approach of occupational social work by addressing various systems, from a micro to macro level, thus highlighting the role of the occupational social worker in maintaining working relationships between these systems. The appropriateness of the ecological systems theory is also confirmed by the above account.

\section{Statutory requirements for practice and registration with professional associations for OSW}

The South African Council for Social Service Professions (2017) stipulates the following requirements for registration and recognition as a specialist in occupational social work (SIOSW):

- Recognised qualification in Social Work and registration as a social worker with the SACSSP; and

- A master's degree and at least two years' practical experience within the scope of occupational social work services; or

- Postgraduate diploma or certificate and three years' practical experience within the scope of occupational social work services; or

- Five years' appropriate practical experience within the scope of occupational social work services.

Furthermore, the South African Occupational Social Workers' Association (2017) stipulates the following requirements for member registration:

- Registration as a social worker within the Republic [of South Africa]; and

- [Current] registration with the SACSSP.

Concerning legislation, all social work practice is governed by the Social Service Professions Act 110 of 1978. The Act necessitates the establishment of a statutory body, the SACSSP, which regulates and ensures ethical conduct and professional social work practice. The SACSSP recognises OSW as a specialist field of social work practice as indicated above. The SAOSWA as a professional body although not recognised as such by the SAQA - represents OSW specialists and practitioners, and its members are subject to the SACSSP code of ethics and the Social Service Professions Act 110 of 1978.

\section{PROBLEM STATEMENT, RATIONALE AND RESEARCH METHODOLOGY}

The rationale for the study is to explore and describe the similarities and differences between EAPs and OSW from a theoretical and practical point of view in order to provide clear and distinct guidelines to potential employers/corporate clients regarding the choice between OSW and EAP when considering the introduction of programmes and services to promote the psycho-social functioning and productivity of employees.

The problem underlying to the rationale to undertaking this study, stems from the confusion which is experienced by different role-players in the fields of OSW and EAPs due to the lack of clarity in terms of similarities and differences between EAPs and OSW. This confusion often impacts on marketing efforts by professionals due to them not being convincing about the embedded and expected value to be added to the lives of employees experiencing psycho-social problems that impact on their productivity.

However, the researchers are of the opinion that, despite their struggles for independence and autonomy, there still seems to be confusion concerning the difference between the EAP and OSW practice within the occupational setting, relating to their purpose, role, function, goals and objectives, scope of practice, service delivery approach and client systems. (Tyson, 2017:3). 
The study is rooted in an interpretivist paradigm, as it aims to conceptualise EAP and OSW theoretically and to explore the participants' subjective experiences of reality, in an attempt to determine the similarities and differences between EAP and OSW in practice. The assumption is that there are multiple realities which can be explored and constructed through human interactions and meaningful actions. These realities are based on the varying experiences, knowledge, views, interpretations, meanings, definitions and perceptions of the participants relating to their fields of practice and workplace settings (Babbie \& Mouton, 2001:28).

Data were collected according to both a qualitative and a quantitative approach - but not according to a typical mixed-method approach, as described by Creswell (2014:217-219). Two sets of data, i.e. the quantitative data collected by one researcher and the qualitative data collected by six researchers with a uniform semi-structured interview schedule were jointly developed. Respondents for the different datacollection tasks were different, although they met the same basic criteria, i.e. members of EAPA-SA and SAOSWA. Respondents were from different geographical areas and the types of interviews implemented were adjusted to ensure feasibility within the different work contexts. No comparison of findings was made as the focus areas between quantitative and qualitative data were different and as such the approach cannot be described as a mixed-method approach. (Creswell, 2014:219). The focus of the quantitative study was on the EAP standards and their application in practice, whilst the focus of the qualitative study was on the scope of services, the client systems, service delivery models and related relevant matters.

The type of research conducted in the proposed study was basic research, as the aim was to acquire knowledge concerning the similarities and differences between EAP and OSW. This was achieved through pursuing exploratory and descriptive research.

The research design best suited for the qualitative part of the study was the collective case study, as the researchers were primarily interested in the meaning participants attach to their personal work-related experiences. The research design best suited for the quantitative component was a non-experimental survey design.

The population for the study includes all the registered members of the Employee Assistance Professionals Association of South Africa (EAPA-SA), approximately 200, and all registered members of the South African Occupational Social Work Association (SAOSWA), approximately 150. However, due to the potential size of these two organisations, it was not realistic to include all the members in the study. Thus, sampling was done from both associations for inclusion in the study. It needs to be emphasised that training up to a master's level in either occupational social work or employee assistance programmes was not a prerequisite for membership of either of these professional associations. This could be interpreted as respondents not having been trained as specialists, despite having been appointed in specialist positions. Purposive sampling was done according to the criteria outlined below.

Participants to the qualitative study had to be registered members of one of the respective associations, EAPA-SA or SAOSWA; must have had at least five years' work experience in their respective fields, either EAP or OSW (although this figure was applied quite flexibly to ensure a sufficient number of participants/respondents). Participants/respondents must have been based in one of the following South African provinces: Gauteng, Northern Cape, Free State or Limpopo (depending on the individual researcher's choice and logistical arrangements).

Sample sizes were dealt with as follows: in the case of individual semi-structured interviews (personal one-on-one, telephone and electronic), each sample consisted of 6 members of EAPA-SA and 6 members of SAOSWA. In the case of focus group interviews, each group consisted of 8 members of EAPA-SA and 8 members of SAOSWA. Digital recordings of the interviews and focus groups sessions were made, with the permission of the participants. All recordings were transcribed, to be used in this form during the data-analysis process. Data quality was ensured through trustworthiness, by focusing on credibility, transferability, dependability and conformability (Anney, 2014:272). Credibility was ensured through member checking. The main author was also responsible for supervision of the other researchers as postgraduate students and dependability was ensured through such external supervision. 
For respondents in the quantitative study, a link to a self-developed questionnaire was provided to respondents via email, which gave them access to an on-line survey, hosted by Qualtrics software programme - available through the University of Pretoria main frame. The first draft of the questionnaire was discussed in a research meeting with fellow authors in order to enhance the validity of the questionnaire. Validity was further enhanced through content validity and face validity of the measuring instrument, criterion validity and construct validity. By implementing the following procedures, the researcher aimed to improve the reliability of the measuring instrument by eliminating items that are unclear; increasing the level of measurement; standardising instructions; maintaining consistent scoring procedure; conducting a pilot study; and moderating the degree of difficulty of the instrument (Pretorius, 2018:9). The questionnaire consisted of questions and no scales.

Emails were sent to 57 registered EAPA-SA members and 59 registered SAOSWA members, making a total of 116. Of the 57 emails sent to EAPA-SA members, seven bounced back as undelivered. In total, 50 emails were delivered to EAPA-SA members and a total of 37 responses were received (74\% response rate). Of the 59 emails sent to SAOSWA members, six bounced back as undelivered, resulting in 53 emails being delivered. A total of $13(24.5 \%)$ SAOSWA members responded to the email to participate in the research.

Schurink, Fouché and De Vos (2011:403) maintain that data analysis is a process consisting of logical and sequential steps which are discussed, with reference to the proposed research study, as follows: preparing and organising data; reducing the data; and visualising, representing and displaying the data.

A pilot study was carried out, simply to avoid uncertainty in terms of the questions to be asked and to avoid unnecessary costs in trying to work with the whole population. The pilot test allowed the researchers to make any changes or inclusions to the respective schedules. The respondents used in the pilot study had been withdrawn from both EAP and OSW samples and results were not included in the main investigation. Due to the logistical challenges expected with the arrangement of a focus group discussion group for pilot purposes, the researchers decided on using the data collected from the pilot focus group discussion.

The researchers and proposed research study complied with the relevant codes of ethical and professional practice. The researchers complied with the following ethical considerations that were relevant to the proposed study as described by Strydom (2011:115-126): voluntary participation; confidentiality; avoidance of harm to respondents; no compensation to respondents/participants; required competence level of researchers; and publication of findings according to initial agreement with respondents and participating member organisations. 


\section{EMPIRICAL DATA ON DIFFERENCES AND SIMILARITIES BETWEEN EMPLOYEE ASSISTANCE PROGRAMMES AND OCCUPATIONAL SOCIAL WORK}

\section{Quantitative empirical data}

\section{TABLE 1 \\ SCOPE OF PRACTICE (ALIGNED TO EAPA-SA STANDARDS) (PRETORIUS, 2018:122)}

\begin{tabular}{|c|c|c|c|c|c|c|c|c|c|c|c|c|c|c|c|c|}
\hline \multirow{3}{*}{$\begin{array}{l}\text { Services offered aligned to EAPA- } \\
\text { SA Standard }\end{array}$} & \multicolumn{8}{|c|}{$\operatorname{EAP}(\mathrm{N}=32)$} & \multicolumn{8}{|c|}{ OSW $(\mathrm{N}=11)$} \\
\hline & \multicolumn{2}{|c|}{ No } & \multicolumn{2}{|c|}{ Yes } & \multicolumn{2}{|c|}{$\begin{array}{l}\text { Missing } \\
\text { Data }\end{array}$} & \multicolumn{2}{|c|}{ Total } & \multicolumn{2}{|c|}{ No } & \multicolumn{2}{|c|}{ Yes } & \multicolumn{2}{|c|}{ Missing Data } & \multicolumn{2}{|c|}{ Total } \\
\hline & $\begin{array}{l}\text { ঠे } \\
\text { 苗 } \\
\text { 之 }\end{array}$ & $8^{\circ}$ & 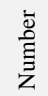 & 8 & $\begin{array}{l}\overrightarrow{\mathrm{D}} \\
\text { है } \\
\text { 乙 }\end{array}$ & 20 & $\begin{array}{l}\overline{\mathrm{D}} \\
\text { 节 } \\
\text { 之 }\end{array}$ & so & $\begin{array}{l}\overline{\mathrm{D}} \\
\text { है } \\
\text { 之 }\end{array}$ & de & $\begin{array}{l}\overline{\mathrm{D}} \\
\overline{\mathrm{E}} \\
\bar{z}\end{array}$ & $\delta^{\circ}$ & $\begin{array}{l}\bar{D} \\
\text { है } \\
\text { 之 }\end{array}$ & $b^{\circ}$ & $\begin{array}{l}\dot{\bar{\nu}} \\
\text { 节 } \\
\text { 乙 }\end{array}$ & $b^{\circ}$ \\
\hline Advisory Committee & 7 & $22 \%$ & 25 & $78 \%$ & 0 & $0 \%$ & 32 & $100 \%$ & 4 & $36 \%$ & 7 & $64 \%$ & 0 & $0 \%$ & 11 & $100 \%$ \\
\hline Organisational Profiling & 5 & $16 \%$ & 25 & $78 \%$ & 2 & $6 \%$ & 32 & $100 \%$ & 0 & $0 \%$ & 11 & $100 \%$ & 0 & $0 \%$ & 11 & $100 \%$ \\
\hline Service Delivery Model & 3 & $9 \%$ & 27 & $84 \%$ & 2 & $6 \%$ & 32 & $100 \%$ & 4 & $36 \%$ & 7 & $64 \%$ & 0 & $0 \%$ & 11 & $100 \%$ \\
\hline Costing Model & 4 & $13 \%$ & 27 & $84 \%$ & 1 & $3 \%$ & 32 & $100 \%$ & 6 & $55 \%$ & 1 & $9 \%$ & 4 & $36 \%$ & 11 & $100 \%$ \\
\hline EAP/OSW Policy & 3 & $9 \%$ & 28 & $88 \%$ & 1 & $3 \%$ & 32 & $100 \%$ & 1 & $9 \%$ & 10 & $91 \%$ & 0 & $0 \%$ & 11 & $100 \%$ \\
\hline Operational guideline & 3 & $9 \%$ & 28 & $88 \%$ & 1 & $3 \%$ & 32 & $100 \%$ & 1 & $9 \%$ & 10 & $91 \%$ & 0 & $0 \%$ & 11 & $100 \%$ \\
\hline Implementation Plan & 2 & $6 \%$ & 29 & $91 \%$ & 1 & $3 \%$ & 32 & $100 \%$ & 2 & $18 \%$ & 9 & $82 \%$ & 0 & $0 \%$ & 11 & $100 \%$ \\
\hline Staffing & 6 & $19 \%$ & 25 & $78 \%$ & 1 & $3 \%$ & 32 & $100 \%$ & 3 & $27 \%$ & 8 & $73 \%$ & 0 & $0 \%$ & 11 & $100 \%$ \\
\hline $\begin{array}{l}\text { Professional consultation and } \\
\text { supervision of staff }\end{array}$ & 5 & $16 \%$ & 26 & $81 \%$ & 1 & $3 \%$ & 32 & $100 \%$ & 1 & $9 \%$ & 10 & $91 \%$ & 0 & $0 \%$ & 11 & $100 \%$ \\
\hline $\begin{array}{l}\text { Professional development of } \\
\text { EAP/OSW staff }\end{array}$ & 9 & $28 \%$ & 23 & $72 \%$ & 0 & $0 \%$ & 32 & $100 \%$ & 1 & $9 \%$ & 10 & $91 \%$ & 0 & $0 \%$ & 11 & $100 \%$ \\
\hline Ensuring Confidentiality & 1 & $3 \%$ & 31 & $97 \%$ & 0 & $0 \%$ & 32 & $100 \%$ & 0 & $0 \%$ & 11 & $100 \%$ & 0 & $0 \%$ & 11 & $100 \%$ \\
\hline Record Keeping & 1 & $3 \%$ & 31 & $97 \%$ & 0 & $0 \%$ & 32 & $100 \%$ & 0 & $0 \%$ & 11 & $100 \%$ & 0 & $0 \%$ & 11 & $100 \%$ \\
\hline Professional Liability Insurance & 12 & $38 \%$ & 20 & $63 \%$ & 0 & $0 \%$ & 32 & $100 \%$ & 4 & $36 \%$ & 7 & $64 \%$ & 0 & $0 \%$ & 11 & $100 \%$ \\
\hline Ethical guidelines & 1 & $3 \%$ & 31 & $97 \%$ & 0 & $0 \%$ & 32 & $100 \%$ & 0 & $0 \%$ & 11 & $100 \%$ & 0 & $0 \%$ & 11 & $100 \%$ \\
\hline Trauma Management & 2 & $6 \%$ & 30 & $94 \%$ & 0 & $0 \%$ & 32 & $100 \%$ & 0 & $0 \%$ & 11 & $100 \%$ & 0 & $0 \%$ & 11 & $100 \%$ \\
\hline Crisis Intervention & 2 & $6 \%$ & 30 & $94 \%$ & 0 & $0 \%$ & 32 & $100 \%$ & 1 & $9 \%$ & 6 & $55 \%$ & 4 & $36 \%$ & 11 & $100 \%$ \\
\hline Assessment of individuals & 0 & $0 \%$ & 31 & $97 \%$ & 1 & $3 \%$ & 32 & $100 \%$ & 0 & $0 \%$ & 11 & $100 \%$ & 0 & $0 \%$ & 11 & $100 \%$ \\
\hline Referral to specialised services & 0 & $0 \%$ & 32 & $100 \%$ & 0 & $0 \%$ & 32 & $100 \%$ & 0 & $0 \%$ & 11 & $100 \%$ & 0 & $0 \%$ & 11 & $100 \%$ \\
\hline Short-term intervention & 0 & $0 \%$ & 32 & $100 \%$ & 0 & $0 \%$ & 32 & $100 \%$ & 0 & $0 \%$ & 11 & $100 \%$ & 0 & $0 \%$ & 11 & $100 \%$ \\
\hline Case Monitoring \& Evaluation & 2 & $6 \%$ & 30 & $94 \%$ & 0 & $0 \%$ & 32 & $100 \%$ & 1 & $9 \%$ & 10 & $91 \%$ & 0 & $0 \%$ & 11 & $100 \%$ \\
\hline Aftercare \& Re-integration & 5 & $16 \%$ & 27 & $84 \%$ & 0 & $0 \%$ & 32 & $100 \%$ & 0 & $0 \%$ & 11 & $100 \%$ & 0 & $0 \%$ & 11 & $100 \%$ \\
\hline Consultation with the organisation & 2 & $6 \%$ & 30 & $94 \%$ & 0 & $0 \%$ & 32 & $100 \%$ & 0 & $0 \%$ & 11 & $100 \%$ & 0 & $0 \%$ & 11 & $100 \%$ \\
\hline Training interventions & 2 & $6 \%$ & 29 & $91 \%$ & 1 & $3 \%$ & 32 & $100 \%$ & 0 & $0 \%$ & 11 & $100 \%$ & 0 & $0 \%$ & 11 & $100 \%$ \\
\hline Marketing & 0 & $0 \%$ & 32 & $100 \%$ & 0 & $0 \%$ & 32 & $100 \%$ & 1 & $9 \%$ & 10 & $91 \%$ & 0 & $0 \%$ & 11 & $100 \%$ \\
\hline Proactive Services & 2 & $6 \%$ & 29 & $91 \%$ & 1 & $3 \%$ & 32 & $100 \%$ & 1 & $9 \%$ & 10 & $91 \%$ & 0 & $0 \%$ & 11 & $100 \%$ \\
\hline Networking & 2 & $6 \%$ & 30 & $94 \%$ & 0 & $0 \%$ & 32 & $100 \%$ & 3 & $27 \%$ & 8 & $73 \%$ & 0 & $0 \%$ & 11 & $100 \%$ \\
\hline $\begin{array}{l}\text { Continuous monitoring \& } \\
\text { evaluation of services }\end{array}$ & 1 & $3 \%$ & 31 & $97 \%$ & 0 & $0 \%$ & 32 & $100 \%$ & 2 & $18 \%$ & 9 & $82 \%$ & 0 & $0 \%$ & 11 & $100 \%$ \\
\hline
\end{tabular}

\section{Discussion of Table 1}

From Table 1 it is evident that most EAP respondents indicated that all the services aligned to the EAPASA Standards document are being offered as part of the EAP service offering. Two components with highest deviation in terms of differences between OSW and EAP were:

- Eighty-four per cent (84\%) of EAP respondents confirmed that various costing models were offered through the EAP, while only $9 \%$ of OSW respondents indicated that different costing models were applied to OSW services;

- Ninety-four per cent (94\%) of EAP respondents noted that crisis intervention formed part of the EAP services to organisations and their employees, while only 55\% of OSW respondents confirmed that crisis intervention forms part of the OSW service offering. 


\section{Scope of practice, service delivery and practise models of OSW and EAPs}

\section{- Similarities between OSW and EAP: A quantitative view}

The majority of services described in the sections focusing on the scope of practice and service delivery are being offered by both the EAP and OSW. These services include: (i) the establishment and management of an advisory committee, organisational profiling, involvement in the decision of a service delivery model, compiling an EAP/OSW policy; (ii) compilation of an operational guideline, designing and implementing an implementation plan for services, staffing of programmes, regular professional consultation and supervision of staff members, professional development of staff, maintaining confidentiality, record keeping; obtaining professional liability insurance, adhering to a set of ethical guidelines; (iii) offering trauma management services, assessment of individuals requiring support, referring individuals to specialised services; (iv) offering short-term interventions, case monitoring and evaluation, rendering aftercare and re-integration services, consultation with the work organisation, offering training interventions, marketing of the services, offering proactive/preventative services, networking; and (v) continued monitoring and evaluation of the entire service offering, offering restorative interventions, offering workplace focused interventions, offering work-person interventions, individual counselling, managerial referrals, family counselling, financial interventions, group trauma interventions, work-family interventions and executive health assessments.

\section{- Differences between OSW and EAP: A quantitative view}

The literature review highlighted that service delivery and practice models have been clearly defined in relation to OSW, while in contrast to this, more emphasis is placed on the core technologies and scope of practice in the EAP field. The empirical investigation emphasised the following as the most prominent differences between OSW and EAP in relation to the scope of practice and service delivery and practice models:

- EAP professionals/practitioners are involved in the decision making relating to costing models, while OSW professionals/practitioners are not involved in this service, or are involved in a more limited way;

- Most EAP respondents indicated that crisis intervention forms part of the EAP services, while only $55 \%$ of OSW respondents noted that this is a service offered through OSW;

- Most OSW respondents indicated that community work is a service offered through OSW, while only a few EAP respondents noted that it is a service offered through the EAP;

- The majority of EAP respondents indicated that EAP services aim to promote human rights practice, social justice and productivity, while fewer OSW respondents confirmed that this forms part of the OSW service delivery;

- A greater percentage of EAP respondents confirmed that legal advice is being offered through the EAP compared to OSW respondents.

\section{QUALITATIVE EMPIRICAL DATA}

The authors had initially considered presenting qualitative findings gathered by different researchers separately, by implication according to a specific geographical area as it was collected. However, repetition of some aspects was experienced. Since it was not seen as important to present data per province, it was decided to rather present data collectively, but with a clear distinction between data obtained from OSW and EAP participants to thereby offer a clear view to the reader of both those perspectives. Aspects unique to certain provinces are, however, presented when relevant and indicated as such - although quite selectively, since this was never expected to be relevant. 


\section{EAP and OSW related key concepts}

The findings of this study showed that EAP practitioners, EAP professionals and EAP specialists have knowledge of the definition of EAP. It was also found that EAP professionals and EAP specialists who are trained social workers or psychometrists had knowledge of the definition of OSW. Despite occupational social workers having shared knowledge of the definition of OSW and EAP, some indicated that it was an easy task, whilst others found it challenging (Mojapelo, 2018:88).

Participant 5 of EAPA-SA (Male, African, Hons SW, public service, 3 years of work experience): The knowledge acquired during the short course made it a bit easier for me in the field of EAP.

Participant 5 of SAOSWA (Female, African, BA SW, public service, 3 years): It wasn't challenging as I am currently studying Masters in Social Work in OSW and also did short course in EAP, and HIV and AIDS in the workplace.

Participant 4 of SAOSWA (Female, African, BA SW, public service, 3 years of service): It was challenging, but after the induction whereby I was exposed to the military, the role of social work in military things became easier.

Occupational social work was understood as (Gunya, 2018:71):

Participant $\mathrm{O} 4$ of SAOSWA (Female, 42 years old, BSW, public servant, 16 years of service): It is a type of social work that is focusing on the workplace meaning that it has to focus on the functioning of individuals within the organisation as well as the organisation itself.

The findings revealed that the definition of EAP reflected the "wellbeing of employees", "to deal effectively with human challenges in the workplace", "productivity within the workplace" and the definition of OSW focused on "more about social work in the workplace", "to assist individuals to cope within the workplace but taking into account a broader society", "generic social work done differently".

With reference to the EAPA-SA participants Gunya (2018:71) shared the following observations:

Participant E6 of EAPA-SA (Female, 46 years old, BSW, public servant, 7 years of work experience): It's a worksite-based programme whereby we assist the employees with their problems - personal problems and we include preventative measures....like awareness.

Participant E1 of EAPA-SA (Female, 43 years old, BSW, mining industry, 6 years of work experience): I believe it's a confidential psychosocial workplace service.

Participant E5 of EAPA-SA (Female, 43 years old, B Psych, public servant, 5 years of work experience): EAP is intended to assist employees in terms of their performance their workplace, supporting them and their families.

The findings of this study also highlighted that EAP practitioners, EAP professionals and EAP specialists play different roles in practice. There are those who are qualified to render clinical services, while some are not qualified to do so. It was found that OSW services are offered only by social workers, including occupational social workers.

\section{Knowledge related to EAP and OSW and the importance of this}

OSW participants revealed a lack of knowledge of core technologies amongst OSWs; they evinced a lack of clarity about the core technologies and the OSW practice model. The study also revealed that both EAP and OSW professionals and practitioners require registration with statutory councils for practising and membership of associations for both EAP and OSW. The findings revealed that there is no specific legislation for OSW and/or EAP; they both rely on the legislation in general (Mojapelo, 2018: 94).

\section{Therapeutic and practice models of EAP and OSW}

The findings have revealed that practitioners in the EAP field mostly use solution-focused brief therapy (SFBT). However, social workers practising in the EAP also apply the systems theory in addition to the 
SFBT. This finding is not alarming as social work as a profession prides itself on its identification with systems theory (Zastrow, 2010). Social workers are exposed to systems theory during their training.

The results further also show that occupational social workers draw on systems theory and other theories such as cognitive behaviour therapy, existential therapy, the strength-focused approach, person-centred approach and the problem-solving approach. Actual knowledge about and views on the motivation for the use of these different models were not explored.

The EAP field is therefore characterised by the use of solution-focused brief therapy, while OSW has mainly adopted ecological systems theory as theoretical foundation.

The researchers also established that in terms of individual counselling, EAP participants render shortterm counselling comprised of about six sessions and then, when necessary, they refer employees for long-term counselling. Both the EAP and the OSW participants do the value of working in a multidisciplinary team, where appropriate.

There are differences between the EAPs and the OSW practice models, as the EAP participants follow the external model and the hybrid model, while the OSW participants follow the in-house model exclusively, which is more of a pillar model with four quadrants namely promotive-educational services; workplace services such as development of policies; restorative-reactive services which are one-on-one; and work-person-colleague sensitivity, which enhances the working relationship of employees such as knowing one another better.

Jacobson and Attridge (2010:18) confirmed the development of two additional models of EAP service delivery which include the "combination" or "hybrid" EAP that typically began as an internal EAP and expanded services to be offered to other workplaces, as well as the "consortium" model, which describes a situation when several smaller companies share the cost of purchasing the EAP.

The team of professionals from different disciplines in the field of EAP ensure the sharing of ideas, which contributes to a broader perspective. OSW, on the other hand, is mainly guided by social work values, principles and its code of ethics.

Under this theme, it was discovered that both EAP and OSW share similar client systems as their service beneficiaries. The other similarities that were identified between the two professions are therapeutic services, proactive programmes, core technologies and the fact that they both focus on workplace problems (Mojapelo, 2018:103). Details on these focus areas were not explored.

\section{Focus of EAP and OSW}

In their interventions, EAP and OSW are likely to differ. The focus of EAPs is mainly on the individual. For instance, when an employee presents with a work-related problem, the EAP practitioner will concentrate on the symptoms and treatment of the employee, often neglecting those factors that could be caused by the organisation. In other words, not intervening with the organisation could lead to the same problems of the employees cropping up repeatedly. On the other hand, OSW focuses on the binocular vision which requires occupational social workers to keep both eyes open simultaneously to give effect to the social work principle of person-in-environment (Van Breda, 2009:298). The findings revealed that occupational social workers focus one eye on the employees and the other on the organisation in order to see the whole situation in greater depth.

The individual focus of EAPs thus differs from the binocular vision of OSW. EAPA-SA promotes prevention/proactive programmes as one of the focus areas within the EAP context (Standards Committee of EAPA-SA, 2015), which may be seen as contradicting the views of the EAP respondents.

\section{Training and staffing of EAP and OSW}

Data have shown that EAP practitioners are trained within different backgrounds and therefore appointed by different professions such as social work, psychology, theology and human resources, amongst many others, whereas occupational social work is staffed with trained social workers only. The findings show 
that although EAP practitioners can be seen as a multidisciplinary profession, social work remains the preferred profession to staff this field. OSW is therefore a specialisation within social work, whereas the EAP is a multidisciplinary profession, although dominated by social workers. It is noteworthy that the SACSSP provides for a specialist category for registration of social workers as 'occupational social workers' - although registration in this category is not a prerequisite for a social worker to become employed as an occupational social worker. Registration as an occupational social worker also implies 'double registration' with the same statutory body.

The results demonstrated that EAP practitioners are affiliated with EAPA-SA as a professional body and occupational social workers are members of SAOSWA. These professional bodies play a huge role in creating networking opportunities and ensuring the professional development of their members. EAPASA is recognised as a professional association by SAQA, whilst SAOSWA does not enjoy the same status and recognition. However, the findings also revealed that some of the EAP practitioners do not provide clinical services to employees, whilst others do. Designations as negotiated between EAPA-SA and SAQA, might be the determining factor in this regard.

EAP participants are registered with their respective statutory bodies (SACSSP or HPCSA) and OSW members are registered with the SACSSP as social workers and not necessarily as occupational social workers.

"EAP is a multidisciplinary field with a large percentage of EAP professionals holding advanced or graduate degrees in social work or psychology" (Jacobson \& Attridge, 2010:24), whereas OSW is confined to a Social Work degree. This phenomenon was confirmed by Gunya (2018:66-67) who stated: "All participants from SAOSWA alluded that they hold a social work degree. In the case of those affiliated with EAPA-SA, of the seven participants four hold a degree in social work; two come from a psychology background; and the remaining one is from an office management background."

Another example was provided by Maruma (2018: 102). Participant J (45 years, female, African, BSW SW SAOSWA) stated that "No. In EAP we can still have a nurse called being in EAP, we can still have a psychologist in EAP we can have a chaplain in EAP, we can have all these other professions in EAP. So, Occupational Social Work is social work; it's a nice designated specialist [field] of social work. So, no, they can't work interchangeably."

The key finding from the theme in terms of the professional requirements shows that there is a slight difference between the EAPs and the OSW in terms of employer-formulated requirements. In occupational social work one needs to have experience in order to practice as an occupational social worker; for example, to work as a warrant officer one should have at least two years' experience and as a captain at least five years' experience. It also became clear that OSW participants were mainly employed in government departments, i.e. the SAPS and the SANDF. This finding correlates with the comment by Van Breda (2009:297) that OSW seems to be more isolated than before, with the majority of occupational social workers working in SAPS and SANDF, and other social workers in the workplace being located in EAPs.

\section{Clinical supervision within EAP and OSW}

The findings do not indicate that clinical supervision in EAPs and OSW differs, but rather identify a lack of supervision in EAPs compared to OSW. All OSW participants confirmed that they do operate under supervision (Gunya, 2018:83) and confirmed that clinical supervision is exercised in the form of individual as well as group supervision.

The results indicated that the basis of this lack of sufficient supervision is the staffing nature of EAPs from multidisciplinary backgrounds. Participants maintained that they are supervised by people with a different training from theirs and therefore they do not receive any supervision which can be described as 'clinical supervision'. 
Participant E1 (Female, 43 years of age, BSW, mining industry for 6 years): No my dear we don't have...I never had that thing since I came here. I don't even have a supervisor, I have a direct manager. Those direct managers it's either a medical practitioner or a nurse or someone from $H R$.

\section{Client systems and appropriate credentials for practice in EAP and OSW}

The findings of this study revealed that EAP beneficiaries consist of employees, family members and the employer organisation, whilst OSW beneficiaries include employees, family members and organisation, and also the community. Mojapelo (2017:89) confirmed this through the following examples:

Participant 6 of EAPA-SA (Male, African, BA SW, Coordinator EH \& W, public service, 1 year of service): We are rendering service to all employees, their immediate family and the organisation.

Participant 2 of SAOSWA (Female, African, BA SW, OSW Supervisor, public service, 16 years of service): We render services to the organisation, employees, and their dependants and also extend our services to the veterans.

\section{Rendering of EAP and OSW services}

According to the findings of this study, EAP uses core technologies such as training and development, marketing, case management, organisational consultation, networking and monitoring and evaluation to activate service delivery in practice, which correlates to a large extent with the description of core technologies by EAPA-SA (Standards Committee of EAPA-SA, 2015). However, it was also found that some EAP practitioners struggled to explain all core technologies used in practice.

Mojapelo (2018: 91) provided the following examples, with reference to the response of participants from OSW when asked about core technologies:

Participant 6 of SAOSWA (Female, African, BA SW, OSW, public service, 2 years of service): They [core technologies] are empathy, confidentiality, social work values and listening skills.

Participant 2 of SAOSWA (Female, African, BA SW, OSW, Public service, 16 years of service): I know of restorative, promotive, work-person intervention and workplace intervention.

With reference to participants from EAP: Participant 1 from EAPA-SA (Female, African, BA SW, Assistant Director, public service, 11 years of service): organisational profile - it help the EAPs to know and understand the culture and dynamics of their organisation; case management - we make sure that confidentiality is maintained and attend to cases timeously and render short-term intervention; marketing - inform our employees about our services; monitoring and evaluation - assist us to check if the EAP services has an impact on the organisation and employees. I use a tool designed to check the satisfaction of clients prior to closing their cases so they can evaluate whether I was able to assist them and give recommendations. We also evaluate the proactive programmes after the presentation to check if the programme was effective, though at times I am forced to assist some employees to evaluate my services and programmes as they cannot write, which makes them be subjective not objective; training and development - we make sure that all our supervisors and line managers understand what EAP is, how to identify a troubled employees, and the different types of referrals.

Findings further showed that the EAP uses standards (programme design, implementation, management and administration, clinical services, non-clinical services, preventative services, networking and monitoring and evaluation) to guide service delivery in practice. The confirmation could be interpreted as positive, compared to findings of a study which was carried out by another group of Master's students on the application of EAP standards in practice (Terblanche, 2015; Terblanche, 2018:518-526). That study confirmed a number of limitations in the day-to-day application of EAP standards, especially in terms of ethical behaviour - although not specifically 'tested' in the current study. 
It was also found that the EAP uses the EHWP strategic framework and policies to complement standards in guiding service delivery. The findings revealed that OSW uses the practice model (restorative, promotive, work-person and organisational interventions) to guide service delivery in practice.

With regard to services rendered by participants from Gauteng province, similarities were confirmed in tasks performed by both the EAPs and the OSW, as both groups are responsible for counselling of employees and their family members, facilitating of programmes (i.e. those dealing with domestic violence, sexual harassment, anger management, substance abuse, stress management) and they apply all the social work methods such as case work, group work and community work (Mbuyisa, 2018: 45).

According to Myeni (2018:118), based on findings in Gauteng and referring to the core technologies, the results confirmed that the EAP and OSW do share very similar functions or core technologies. Consulting with work organisations, marketing, case management, assessments and support services and stakeholder management and networking were all considered common features of OSW and EAPs. Assessments and support services seemed to be the most leading function, as all participants reported on providing assessments and counselling to all employees.

Consultations with work organisations and networking were also prevalent. However, marketing seemed to have reflected less in OSW when compared to EAP. The EAP was slightly contradictory, whereby marketing was strongly emphasised both in literature and in practice. Consultation with the work organisations seems to be present in both fields. Case management was present in both fields; however, in OSW the function was not strongly highlighted in the literature despite being carried out in practice. In the EAP, case management seemed to be part and parcel of daily functions, to have a robust presence and be guided by the literature as well as practice. Stakeholder management and networking were also part of both practices (Myeni, 2018:131).

\section{Service delivery/practice models in EAPs and OSW}

It was determined that the service delivery models in the EAP and OSW were not complementary. Service delivery or practice models in OSW were more fixated on interventions, and being work-person focused, promotive, restorative and organisational, whereas the EAP was more based on where interventions would take place. This was reflected through the in-house, external house and hybrid models.

\section{Scope of practice in EAPs and OSW}

The scope of practice in both OSW and EAPs is taken note of to guide the actual functions, interventions and services to the client systems and to what extent they take place. All the participants noted that their respective statutory bodies provide the guidelines for ethical practice and codes of conduct. EAP participants strongly favoured the 'EAPA-SA EAP Standards' and 'Code of Ethics' documents and OSW participants also favoured the SACSSP standards for practice. Furthermore, the scope of practice is prescribed by the employers of occupational social workers and EAP practitioners.

In this regard, Van Breda's (2009:297) point should be kept in mind, as he stated that occupational social workers are mainly employed by the SAPS and the SANDF. Both these departments are military in nature, where a specific organisational culture may be expected that may have an influence on the dayto-day functioning of OSW services being rendered. One may expect services in a 'service-rendering' environment to be different from those in a typical business environment, which may be driven by a different set of principles like profit-making as the bottom line, co-responsibility for budgeting and return-on-investment.

\section{SUMMARY OF DIFFERENCES AND SIMILARITIES BETWEEN EAP AND OSW}

See Table 2 for a summary on similarities and differences between occupational social work and employee assistance programmes. 
TABLE 2

SUMMARISED COMPARISON BETWEEN EMPLOYEE ASSISTANCE PROGRAMMES AND OCCUPATIONAL SOCIAL WORK

\begin{tabular}{|c|c|c|c|}
\hline & Occupational Social Work & Employee Assistance Programmes & $\begin{array}{l}\text { Similarities/ } \\
\text { differences }\end{array}$ \\
\hline Qualifications & $\begin{array}{l}\text { Qualifications prescribed for } \\
\text { OSW }\end{array}$ & $\begin{array}{l}\text { EAP is flexible in terms of the qualification } \\
\text { requirements to practice }\end{array}$ & Different \\
\hline Registration with statutory body & Compulsory & $\begin{array}{l}\text { Recommended to register with existing } \\
\text { statutory body - but no EAP specific statutory } \\
\text { body in existence }\end{array}$ & Different \\
\hline $\begin{array}{l}\text { Membership with professional } \\
\text { body }\end{array}$ & $\begin{array}{l}\text { Association (SAOSWA) not } \\
\text { acknowledged as professional } \\
\text { association }\end{array}$ & $\begin{array}{l}\text { Association (EAPA-SA) acknowledged as } \\
\text { professional association }\end{array}$ & Different \\
\hline $\begin{array}{l}\text { Membership } \\
\text { categories/designations }\end{array}$ & Non-existent & $\begin{array}{l}\text { Four designations: } \\
\text { EAP coordinator } \\
\text { EAP practitioner } \\
\text { EAP professional } \\
\text { EAP specialist }\end{array}$ & Different \\
\hline Specific legislation & $\begin{array}{l}\text { South African White Paper on } \\
\text { Social Welfare (1997) }\end{array}$ & None & Different \\
\hline Staffing & $\begin{array}{l}\text { Social workers, some specialists } \\
\text { in occupational social work }\end{array}$ & $\begin{array}{l}\text { Multi-disciplines, dominated by social workers, } \\
\text { plus psychologists, human resources } \\
\text { management practitioners, nursing } \\
\text { professionals, }\end{array}$ & Different \\
\hline Clinical supervision & Part of clinical practice & Not commonly applied & Different \\
\hline Key performance indicators & $\begin{array}{l}\text { Meant to ensure employee and } \\
\text { organisational wellness }\end{array}$ & $\begin{array}{l}\text { Meant to ensure employee and organisational } \\
\text { wellness }\end{array}$ & Similar \\
\hline Terminology & $\begin{array}{l}\text { Work-based programmes, } \\
\text { troubled employees, personal and } \\
\text { work-related problems, } \\
\text { productivity and job performance }\end{array}$ & $\begin{array}{l}\text { Work-based programmes, troubled employees, } \\
\text { personal and work-related problems, } \\
\text { productivity and job performance }\end{array}$ & Similar \\
\hline Service objectives & $\begin{array}{l}\text { Promotion of the physical and } \\
\text { mental health of employees, } \\
\text { work-life balance and the } \\
\text { productivity of the workforce. }\end{array}$ & $\begin{array}{l}\text { Promotion of the physical and mental health of } \\
\text { employees, work-life balance and the } \\
\text { productivity of the workforce. }\end{array}$ & Similar \\
\hline Evaluation & Non-confirmation & $\begin{array}{l}\text { Confirmation of indicators - mainly monetary } \\
\text { in terms of targets reached, work carried out. }\end{array}$ & Different \\
\hline Service delivery models & Mainly in-house & $\begin{array}{l}\text { In-house } \\
\text { External/contracted } \\
\text { Hybrid }\end{array}$ & Different \\
\hline Guiding document & Non-existent & EAPA-SA EAP Standards document 2015 & Different \\
\hline Client systems & $\begin{array}{l}\text { Employees, family members and } \\
\text { the employer organisation }\end{array}$ & $\begin{array}{l}\text { Employees, family members and the employer } \\
\text { organisation }\end{array}$ & Similar \\
\hline Therapeutic approaches & $\begin{array}{l}\text { Task-centred, strengths focused } \\
\text { and brief therapy. }\end{array}$ & $\begin{array}{l}\text { Family therapy, person-centred therapy, } \\
\text { cognitive behavioural therapy (confirmed by } \\
\text { only one EAP participant) and solution-focused } \\
\text { brief therapy. }\end{array}$ & $\begin{array}{l}\text { Different but with } \\
\text { strong correlation }\end{array}$ \\
\hline Status & Acknowledged as profession & Not acknowledged by legislation & Different \\
\hline
\end{tabular}

The concepts used to describe OSW and EAPs were similar. These included words like work-based programmes, troubled employees, personal and work-related problems, productivity and job performance. The service objectives in both fields are based on the promotion of the physical and mental health of employees, work-life balance and the productivity of the workforce.

A difference between the EAP and OSW is that the EAP is flexible in terms of the qualification requirements to practice in these fields. Registration with a statutory body is compulsory in the case of OSW, whilst such registration for EAPs is not possible as there is no statutory body, unless counselling is performed as one of the core functions of the EAP, in which case registration according to the basic qualification is required, i.e. as social worker or psychologist. Differentiation in terms of membership of EAPA-SA, which is facilitated by four different designations as acknowledged by SAQA, needs to be taken into consideration in this context. 
The findings further indicated that the participants did not seem to understand the distinction between statutory registration and voluntary membership with an association. They believed that a lack of registration had dire consequences and thought of this as an illegal practice. They also indicated that registration and membership with an association ensured the protection of professionals and the profession, not acknowledging or realising that malpractice insurance needs to be arranged in addition to registration with a statutory body or membership with a professional organisation. It was also confirmed that EAPs are guided by the EAP Standards document (Standards Committee of EAPA-SA, 2015:9-10), which outlines how EAPs should be executed. The lack of a similar 'guiding' document for OSW was evinced.

The similarities between EAP and OSW are the fact that the EAP is designed to deal with the work- and non-work-related problems that affect the employees, their families and the organisation, and OSW also addresses the very same issues. The findings further indicated that the kind of employee issues that are dealt with range from substance abuse, stress, trauma, financial difficulties, conflict, absenteeism and employee development to bereavement. The programmes and services rendered by EAP practitioners/professionals and OSWs are closely linked to their roles and functions. The findings on the programmes and services offered by EAPs were in line with the EAP scope of practice where individual counselling/casework includes assessments, referrals, follow-up and reintegration as well as group work and community work with wellness and work-life programmes often integrated into the EAP. On the other hand, the OSW programmes and services are guided by the occupational social work practice model. Programmes rendered were restorative, promotive, work-person and workplace intervention focused.

The key performance indicators for EAPs and OSW practitioners are similar in that they are meant to ensure employee and organisational wellness. The KPIs are measured in terms of work done and the success of programmes. EAPs are, however, evaluated according to the targets reached, which is mostly driven by monetary considerations (Attridge, 2009:389-390). With regard to OSW, no such confirmation could be found.

In the EAP field, the service delivery model identified included the in-house, external and the hybrid models, whilst the OSW operates mainly according to the in-house model.

The therapeutic approaches used in EAPs range from family therapy, person-centred therapy, cognitive behavioural therapy (confirmed by only one EAP participant) and solution-focused brief therapy. The therapeutic models used in OSW, on the other hand, include task-centred, strengths focused and brief therapy. The common approach used in both fields was solution focused brief therapy (Modise, 2018:107). EAP functions and programmes are directed by the service delivery model prescribed and supported by the respective organisation to which they are contracted. No significant differences in this regard could be confirmed between the EAP and OSW practice.

EAPs and OSW are interrelated but have distinct features. OSW is regarded as a profession because all OSW practitioners are trained social workers, whereas EAPs employ people from different professions such as psychologists and counsellors. EAPs are, however, seen as more advanced than OSW in terms of the scope of practice and function within a more structured framework.

\section{CONCLUDING REMARKS}

Differences and similarities have been found to be a reality through an extensive study amongst members of EAPA-SA and SAOSWA as part of Master's students' research.

Similarities in terms of service delivery between OSW and the EAP seem to be a greater reality than their differences.

A major difference, however, is the fact that OSW is bound or limited to a certain category of government departments - with limited if any growth over the last two decades. The EAP has grown tremendously from the first formal EAP being implemented in the mid-1980s in the mining industry to EAPs currently 
found in almost all sectors of industry and public service. Exceptional growth was experienced in the EAP service provider sector, which also stimulated private practice, especially benefitting social workers in private practice. No OSW service providers had been created or could be confirmed as employers of participants.

It would be fair and realistic to state that the differences between EAP and OSW are more of a cosmetic nature and are mostly maintained by role-players to protect their own turf. However, the concepts of the EAP and OSW cannot be used interchangeably because the EAP depends on individuals who have studied in a variety of fields, e.g. psychology, social work, human resource management to name a few, whereas OSW is staffed by social workers exclusively (Maruma, 2018:107).

This study confirmed that the EAP is indeed a specialist inter-disciplinary programme with a foot in industry and which is experiencing a growing curve, whereas OSW is a specialisation field in social work, safeguarded by law and limited to the public sector. The dominating in-house model found within OSW may create a more protected work environment for OSW practitioners with less exposure to the financial component and justification of its existence in the workplace. As such, occupational social work will most likely remain a reality in practice within a public service environment, whilst the employee assistance programme will thrive in the private sector, which is a much stronger profit-driven environment. This concluding remark may highlight the challenge in terms of a choice to be made between the most appropriate framework for services, i.e. occupational social work or employee assistance programmes.

\section{REFERENCES}

AKABAS, S.H. 1995. Occupational social work. In: Edwards, R.L. Encyclopaedia of Social Work. (19 ${ }^{\text {th }}$ ed). Washington, DC: National Association of Social Work: 1779-1786.

ANNEY, V.N. 2014. Ensuring the quality of the findings of qualitative research: Looking at trustworthiness criteria. Journal of Emerging Trends in Educational Research and Policy Studies, 5(2):272-281.

ATTRIDGE, M. A. 2009. Employee Assistance Programs: A Research-Based Primer. In: COOPER G.L., QUICK, J.C. \& SCHABRACQ M.J. (eds). Handbook of work and health psychology. Wiley Blackwell, 381- 405. [Online] Available: file:///C:/Users/u02388936/Downloads/Attridge2009WileyHandbookofWorkHealthPsych-EAPChapter.pdf [Accessed 01/04//2020].

BABBIE, E. \& MOUTON, J. 2001. The practice of social research. Cape Town: Oxford University Press.

BARKER, R.L. 2003. The social work dictionary. Washington, DC: National Association of Social Workers

CHU, C. 1994. An integrated approach to workplace health promotion. Ecological Public Health: From Vision To Practice: $182-195$.

CRESWELL, J.W. 2014. Research design: Qualitative, quantitative \& mixed methods approaches, Los Angeles: SAGE Publications Inc.

DORKIN, M. 2009. Coaching: An innovative new methodology for occupational social workers. Johannesburg: Witwatersrand University. (MSW mini dissertation)

DU PLESSIS, A.W. 1994. Issue resolution in the evolvement of occupational social work practice in South Africa. Johannesburg: University of Witwatersrand. (Doctoral dissertation)

EMPLOYEE ASSISTANCE PROFESSIONALS ASSOCIATION OF SOUTH AFRICA (EAPA-SA), 2016. History and overview. [Online] Available: http://www.eapasa.co.za/eapa-sa-profile/ [Accessed 16/04/2017].

EMPLOYEE ASSISTANCE PROFESSIONALS ASSOCIATION OF SOUTH AFRICA (EAPA-SA). 2015. Standards for Employee Assistance Programs in South Africa. [Online] Available: http://www.eapasa.co.za/wpcontent/uploads/2016/07/EAPA-SA-Standards-3rd-Edition-September-2010.pdf [Accessed 18/02//2017].

GORNICK, M.E. \& BLAIR, B.R. 2005. Employee assistance, work-life effectiveness, and health and productivity: A conceptual framework for integration. In: ATTRIDGE, M., HERLIHY, P.A. \& MAIDE, R.P. The integration of employee assistance, work/life, and wellness services. New York: The Haworth Press Inc.:1 - 29.

GUNYA, T. 2018. A comparative study between Employee Assistance Programmes and Occupational Social Work in the Free State and Gauteng regions, South Africa. Pretoria: University of Pretoria. (MSW mini dissertation) 
IVERSEN, R.R. 1998. Occupational social work for the $\mathbf{2 1}^{\text {st }}$ century, Social Work. 43(6):551-556. https://doi.org/10.1093/sw/43.6.551

JACOBSON, J. M., \& ATTRIDGE, M. 2010. Employee Assistance Programs (EAPs): An allied profession for work/life. In: SWEET, S \& J. CASEY. (eds). Work and Family Encyclopaedia. Chestnut Hill, MA: Sloan Work and Family Research Network. Available: http://wfnetwork.bc.edu/encyclopedia entry.php?id=17296\&area=All

KHUBEKA, M.D. 2015. Non-clinical service practice standards in South African Employee Assistance Programmes. Pretoria: University of Pretoria. (MSW mini dissertation)

KRUGER, A. \& VAN BREDA, A.D. 2001. Military social work in the South African National Defence Force. Military Medicine, 166(11):947-951.

MAIDEN, R.P. 2001. (Ed). Global perspectives of occupational social work. New York: The Haworth Press.

MARUMA, M.R. 2018. A comparative study between Employee Assistance Programmes and Occupational Social Work in Gauteng Province, Pretoria: University of Pretoria. (MSW mini dissertation)

MODISE, T.C. 2018. A comparative study between Employee Assistance Programmes and Occupational Social Work in a South African context. Pretoria: University of Pretoria (MSW mini dissertation)

MBUYISA, K. H. 2018. A comparative study between Employee Assistance Programmes and Occupational Social Work In The Gauteng Province, South Africa. Pretoria: University of Pretoria. (MSW mini dissertation)

MOGOROSI, L. 2009. Employee Assistance Programs: Their rationale, basic principles and essential elements. Social Work/Maatskaplike Werk, 45(4):343-359.

MOJAPELO, K.I. 2018. A comparative study between Employee Assistance Programmes and Occupational Social Work in the South African context: Limpopo Province. Pretoria: University of Pretoria. (MSW mini dissertation)

MOR BARAK, M.E. \& BARGAL, D. 2000. Social services in the workplace: Repositioning social work in the new millennium. Los Angeles: The Haworth Press.

MULVIHILL, M.D. 2005. Health and productivity measurement: The integration of health and wellness into employee assistance and work-life programs. In: ATTRIDGE, M., HERLIHY, P.A. \& MAIDEN, R.P. The integration of employee assistance, work/life, and wellness services. New York: The Haworth Press Inc.:57 - 66.

MYENI, N.V. 2018. A comparative study between Employee Assistance Programmes and Occupational Social Work in the Gauteng Province. Pretoria: University of Pretoria. (M Soc Sci mini dissertation)

NAICKER, R. \& FOUCHÉ, C. 2003. The evaluation of an insourced Employee Assistance Programme. S.A. Journal of Human Resource Management, 1(1), 25-31.

PARAST, S.M. \& NIYA, H.A. 2015. The roles of occupational social workers in workplace: With regard to social capital. MAGNT Research Report, 3 (1):1118-1123. doi: dx.doi.org/14.9831/1444-8939.2015/3-1/MAGNT.110

PATEL, L. 2016. Social welfare and social development $\left(2^{\text {nd }} e d\right)$. Cape Town: Oxford University Press Southern Africa.

PAYNE, M. 2015. Modern social work theory. $\left(4^{\text {th }}\right.$ ed). New York: Oxford University Press.

PRETORIUS, M. 2018. A comparative study between Employee Assistance Programmes and Occupational Social Work: A quantitative view. Pretoria: University of Pretoria. (MSW mini dissertation)

ROMAN, P.M. \& BLUM, T.C. 1985. The core technology of employee assistance programs. The Almacan, 15(3), 8-9, 1619.

SCHURINK, W., FOUCHÉ, C.B. \& DE VOS, A.S. 2011. Qualitative data analysis and interpretation. In: De VOS, A.S., STRYDOM, H., FOUCHé, C.B. \& DELPORT, C.S.L. Research at grass roots for the social sciences and human service professions. $\left(4^{\text {th }}\right.$ ed). Pretoria: Van Schaik Publishers.

SOUTH AFRICAN COUNCIL FOR SOCIAL SERVICE PROFESSIONS (SACSSP). 2017. Scope of practice: Social work final draft. [Online] Available: https://www.sacssp.co.za/Professionals/download/12 [Accessed 16/04/2017].

SOUTH AFRICAN OCCUPATIONAL SOCIAL WORKERS' ASSOCIATION (SAOSWA). 2017. Overview. [Online] Available: http://saoswa.co.za/About [Accessed 16//04/2017].

SOUTH AFRICAN QUALIFICATIONS AUTHORITY (SAQA), 2019. SAQA: Professional Designation: Employee Assistance Coordinator. [Online] Available: (https://pbdesig.saqa.org.za/viewProfessionalDesignation.php?id=839) [Accessed 18/08/2020].

SOUTH AFRICAN QUALIFICATIONS AUTHORITY (SAQA), 2019. SAQA: Professional Designation: Employee Assistance Specialist. Available: (https://pbdesig.saqa.org.za/viewProfessionalDesignation.php?id=840) [Accessed 2020/08/18]. 
SOUTH AFRICAN QUALIFICATIONS AUTHORITY (SAQA), 2019. SAQA: Professional Designation: Employee Assistance Practitioner. [Online] Available: (https://pbdesig.saqa.org.za/viewProfessionalDesignation.php?id=495) [Accessed 18/08/2020].

SOUTH AFRICAN QUALIFICATIONS AUTHORITY (SAQA), 2019. SAQA: Professional Designation: Employee Assistance Professional. [Online] Available: https://pbdesig.saqa.org.za/viewProfessionalDesignation.php?id=496 [Accessed 18/08/2020].

STANDARDS COMMITTEE OF THE EMPLOYEE ASSISTANCE PROFESSIONALS ASSOCIATION OF SOUTH AFRICA (EAPA-SA), 2015. EAPA-SA EAP Standards, Pretoria.

STRAUSSNER, S.L.A. 1990. Occupational social work today. New York: Haworth Press.

STRYDOM, H. 2011. Ethical aspects of research in the social sciences and human professions. In: DE VOS, A.S., STRYDOM, H., FOUCHé, C.B. \& DELPORT C.S.L. Research at grass roots for the social sciences and human service profession. $\left(4^{\text {th }}\right.$ ed). Pretoria: Van Schaik Publishers.

STUTTERHEIM, E. \& WEYERS, M.L. 2004. Strengths-focused intervention: the new approach of the Social Work Service of the South African Police Service (SAPS). Social Work, 40(1):1-14.

TERBLANCHE, L.S. 2015. Report on the application of EAPA-SA Standards in practice: Survey as baseline for revision of EAPA-SA Standards. Pretoria: University of Pretoria (Unpublished report on student research project)

TERBLANCHE, L.S. 2018. Creating legacy in EAP business: The South African approach towards employee assistance. Sandton: St Paul \& John Publishers.

TERBLANCHE, L.S. 2019. Employee Assistance Programmes: History and standards, Short course on Employee Assistance Programmes. Pretoria: University of Pretoria.

THE SOCIAL SERVICE PROFESSIONS ACT 110 OF 1978, section 28(1)(gA): Regulations relating to the registration of a specialty in occupational social work, 2010. Government Gazette, (32886) Pretoria: Government Printer.

TYSON, W. 2017. A comparative study between Employee Assistance Programmes and Occupational Social Work in theory and practice. Pretoria: University of Pretoria. (Research proposal for MSW dissertation)

VAN BREDA, A.D. 2009. The scope of occupational social work in South Africa. The Social Work PractitionerResearcher, 21(3):284-300.

WHITE PAPER ON SOCIAL WELFARE.1997. Government Gazette Notice 1108 of 1997, Notice 1108 of 1997. Regulation 5(2). Pretoria: Government Printer.

WILLIAMS, M. 2016. Police Social Work in South Africa, Social Work, 52 (1):130-143.

ZASTROW, C. 2010. Introduction to social work and social welfare. (10th ed). USA: Brooks/Cole. 